Saudi Journal of Oral and Dental Research

Abbreviated Key Title: Saudi J Oral Dent Res

ISSN 2518-1300 (Print) |ISSN 2518-1297 (Online)

Scholars Middle East Publishers, Dubai, United Arab Emirates

Journal homepage: https://saudijournals.com

Case Report

\title{
Role of Unique Identification Number and Barcode of Aadhaar in Forensic Odontology
}

\author{
Dr. Puja Harie Priya M.S MDS ${ }^{1}$, Dr. J. Brintha Jei MDS ${ }^{2 *}$, Dr. K. Murugesan MDS ${ }^{3}$ \\ ${ }^{1}$ Senior Lecturer, Department of Prosthodontics, Ragas Dental College, Uthandi, Chennai, India \\ ${ }^{2}$ Associate Professor, Department of Prosthodontics, SRM Dental College, Ramapuram, Chennai, India \\ ${ }^{3}$ Professor, Department of Prosthodontics, SRM Dental College, Ramapuram, Chennai, India
}

DOI: $\underline{\text { 10.36348/sjodr.2021.v06i04.002 }}$ | Received: 03.03.2021 | Accepted: 02.04.2021 | Published: 11.04 .2021

*Corresponding author: Dr. J. Brintha Jei

\section{Abstract}

Forensic science is an application of scientific knowledge and methodology to criminal investigation and legal problems. Forensic dentistry is the branch which comes under this forensic science that deals with proper handling, examination and evaluation of dental evidence that is presented in interest of justice. Here the dental knowledge is applied to criminal and civil laws. A prosthodontist play a major role in fabrication of prosthesis as identification tool for requirement of medicolegal investigation. This article describes about labelling a denture using Aadhaar card barcode and unique identification number which will be useful for investigation.

Keyword: Identification marking, Denture labelling, Aadhaar card.

Copyright $\odot$ (2021 The Author(s): This is an open-access article distributed under the terms of the Creative Commons Attribution 4.0 International License (CC BY-NC 4.0) which permits unrestricted use, distribution, and reproduction in any medium for non-commercial use provided the original author and source are credited.

\section{INTRODUCTION}

Dr. Oscar Amoedo is the father of forensic odontology his work was established and published in year 1898 and in 1970 it was defined by Keiser-Neilson as a branch of forensic medicine that deals with the proper handling and examination of dental evidence with proper evaluation and presentation dental findings. Dental identification is most vital for any medico-legal investigation to deliver proper justice. American board of forensic odontology had given guidelines for dental identification based on prosthetic devices/missing teeth, caries and restorations [1]. A prosthodontist play a major role in fabrication of prosthesis which was used as identification tool for investigation. Denture marking or labelling is used for identifying a person in a geriatric institutions or post mortem during crimes, war and mass disasters [2, 3] and can also be used for patients who present with loss of memory and unconsciousness. In this case report bar coding method is used it is an automatic identification technology that allows the data to be collected rapidly and accurately of a person, company etc.

\section{CASE REPORT}

A patient named Mr. Subbiah of 65 years reported to department of prosthodontics with the chief complaint of lost denture for past 3 months the patient was retired army personal and now works as security in bank. A detailed case history was taken and patient does not have any relevant medical history. His past dental history was he had extracted all his teeth one year back. On clinical examination patient had a normal residual ridge (Fig 1).

Since the patient had missed the denture, he was unable to remember the misplacing of his dentures and the patient also work as a security in bank if there was any incidence of crime like robbery or fire situations or any other way of disaster to be happened in bank the only way of identifying him would be identification marks on the denture. So we decided to use Bar code [4-8] in maxillary and unique identification Aadhaar number in mandibular complete dentures.

- Secondary impressions were made using zinc oxide eugenol.

- The maxillary and mandibular complete denture was fabricated in the conventional manner. The processed denture was retrieved from the flask, the excess trimming was done.

- The Aadhar card had the QR code and the Aadhaar number and the plan was to incorporate the $\mathrm{QR}$ code in the maxillary denture and the Aadhaar 
number in the mandibular denture. On the polished surface in the palatal region of the maxillary denture $12 \mathrm{~mm} \times 12 \mathrm{~mm}$ square space with depth of $1.25 \mathrm{~mm}$ was created. On the polished surface in the lingual region of the mandibular denture $5 \mathrm{~mm} \times 15 \mathrm{~mm}$ rectangular space with depth of 1.25 mm was created.

- This 2D QR code of the Aadhaar card contains information such as name, age, gender, address, phone number and security number with a code and the Aadhaar number also contain all these demographic data's.

- This QR code and Aadhaar number was made to size $1 \mathrm{~mm}$ less of the space created in the denture and is printed in a photographic sheet which was then laminated (Fig 2) so that the oral fluid or the methyl acrylate liquid does not dissolve the sheet.

- The laminated sheet was placed in the space created and sealed using clear auto-polymerizing resin (Fig 3).

- Then the denture was finally polished and was inserted into patients mouth. The QR code was scanned using the mobile (Fig 4) which had the decoder its was observed that the code was deciphered.

- Then the code was transformed to text where all information provided in Aadhaar card regarding patient was displayed as text in the mobile. Patient was satisfied with the denture (Fig 5).

- Post-operative instruction regarding maintenance of denture was given.

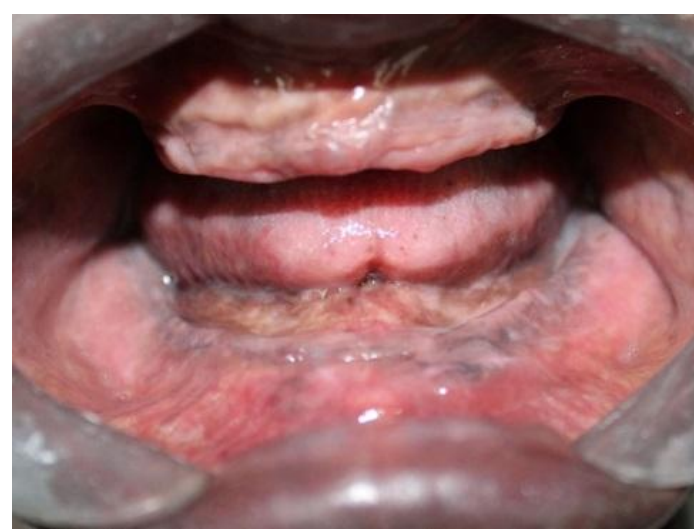

Fig-1: Intra oral view

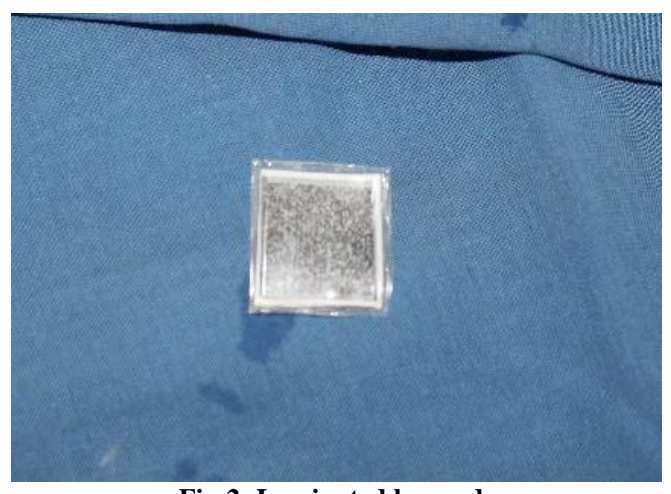

Fig-2: Laminated bar code

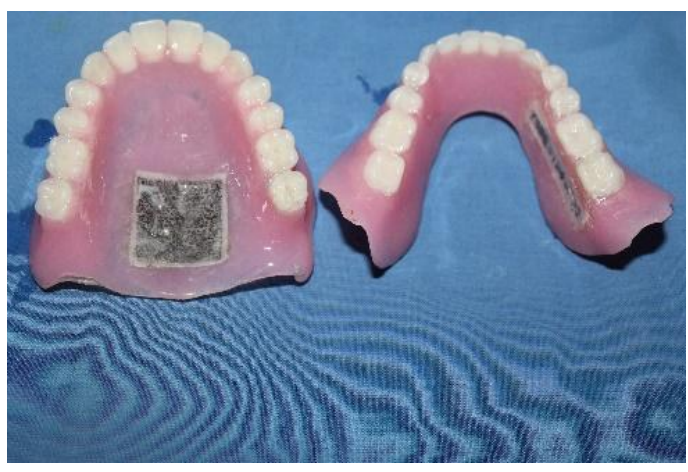

Fig-3: Incorporated Aadhaar QR code in maxillary and unique identification number in mandibular denture

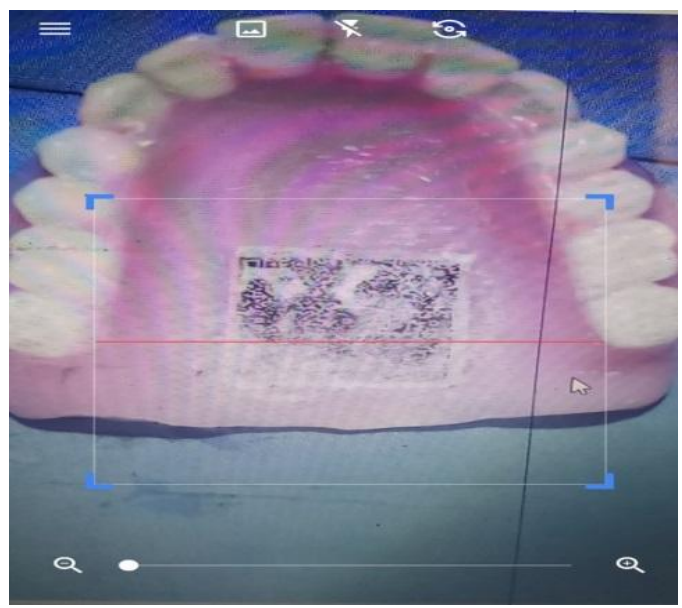

Fig-4: Scanning of Bar code using mobile phone

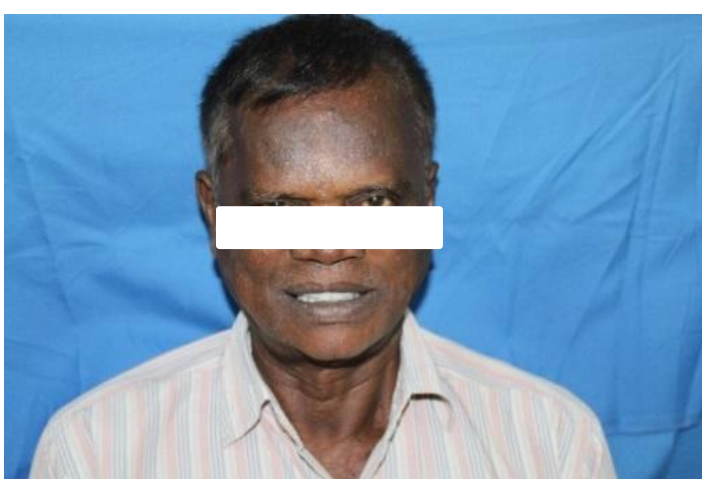

Fig-5: Extra oral view of the patient

\section{DISCUSSION}

During recent decades the period of edentulism has been decreased due to awareness of oral health among the people and advancements in dentistry. Having in mind about the very limited data available as medical and dental records for forensic science. An idea of incorporating code and number in the denture was developed to have an easy track on a person. This method is very simple, budget friendly and does not require any difficult or special laboratory techniques for it to be incorporated. So there is a need for the legal and social investigations. American dental association in the year of 1982 has also uplifted the process of denture labelling in prosthesis. This kind of identification can 
Puja Harie Priya et al; Saudi J Oral Dent Res, Apr, 2021; 6(4): 148-150

also be used for old age people who have lost their memory, in missing cases which would be more helpful. Richmond et al. stated few important requirements of bar code identification marker has it was placed in the maxillary or mandibular molar region palatally or lingually so that it would protect from heat by use of the tongue [9-12]. Rajendran et al. has done a study using a 2D bar code incorporated into maxillary denture and had used the software the decoder translated code into text having basic information of an individual [5-13].There were many studies done by various authors which had many other identification techniques such has Radiographic Technique where Michael Reason et al. had Incorporated Lead foil Invisible. Denture Identification, Milward Shepherd et al. had used Automatic Identification of Dental Appliances, Hideo Matsumura et al. had Incorporated Cast Embossed Identification Plate into a Partial Denture Framework [14-16]. But all these methods had some or other drawbacks.

So this study was done using Aadhaar card's QR code and Aadhar number incorporated into the dentures this was a comfortable method of acquiring information about an individual during his or her presence or absence in an investigation.

\section{CONCLUSION}

In medicolegal issues and forensic investigations the identification marker like Aadhaar OR code and number play a major role as evidence in all kind of investigations. They are also used for elderly patient who have lost their denture by decreasing the anxiety, tension. Thus this method should become mandatory in order to avoid confusions, betterment of lifestyle and improve the speed of investigations.

\section{REFERENCES}

1. Ryan, L. D., Keller, J. B., Rogers, D. E., \& Schaeffer, L. (1993). Clear acrylic resin T-bar used in denture identification. The Journal of prosthetic dentistry, 70(2), 189-190.

2. Berry, F. A., Logan, G. I., Plata, R., \& Riegel, R. (1995). A postfabrication technique for identification of prosthetic devices. Journal of Prosthetic Dentistry, 73(4), 341-343.

3. Cunningham, M., \& Hoad-Reddick, G. (1993). Attitudes to identification of dentures: the patients' perspective. Quintessence International, 24(4).
4. Gujjalapudi, M., Anam, C., Mamidi, P., Saxena, A., Kumar, G., \& Rathinam, J. (2013). The new ID proof: A case report of denture labeling. Journal of Orofacial Research, 63-65.

5. Rajendran, V., Karthigeyan, S., \& Manoharan, S. (2012). Denture marker using a two-dimensional bar code. Journal of Prosthetic Dentistry, 107(3), 207-208.

6. Nagpal, A., Duvedi, K., \& Singla, A. (2020). Denture labelling: An ID proof in dentistry. IP Annals of Prosthodontics and Restorative Dentistry, 4(2), 31-34.

7. Thomas, T., Muruppel, A. M., Dinesh, N., Gladstone, S., \& George, N. (2014). Dentures in Forensic Identification-A Review of Methods \& Benefits. J Adv Med Dent Sci, 2, 85-94.

8. Mohan, J., Kumar, C. D., \& Simon, P. (2012). "Denture marking" as an aid to forensic identification. The Journal of Indian Prosthodontic Society, 12(3), 131-136.

9. El-Gohary, M., Saad, K. M., El-Sheikh, M. M., \& Nasr, T. M. (2009). A new denture labeling system as an ante-mortem record for forensic identification. Mansoura Journal of Forensic Medicine and Clinical Toxicology, 17(2), 79-86.

10. Meenakshi, A., Meena, N. S., Bharti, V., \& Suganthapriya, S. (2017). Special dentures. SRM Journal of Research in Dental Sciences, 8(3), 126.

11. Kareker, N., Aras, M., \& Chitre, V. (2014). A review on denture marking systems: a mark in forensic dentistry. The Journal of Indian Prosthodontic Society, 14(1), 4-13.

12. Richmond, R., \& Pretty, I. A. (2006). Contemporary methods of labeling dental prostheses-A review of the literature. Journal of forensic sciences, 51(5), 1120-1126.

13. Pankaj, D., \& Sonia, S. (2010). The various methods and benefits of denture labelling. J Forensic Dent Sci, 2, 53-58.

14. Clark, D.H., Cainio, P (eds). (1992). Practical forensic dentistry. Butterworth-Heinemann, Boston

15. Haines, D.H. (1973). Identification in mass disasters from dental prosthesis. Int $\mathbf{J}$ Forensic Dent, 1:11-5.

16. Stavrianos, C. H., Petalotis, N., Metska, M., Stavrianou, I., \& Papadopoulos, C. H. (2007). The value of identification marking on dentures. Balkan Journal of Stomatology, 11(3), 212-216. 